Int. J. Plant Sci. 175(5):544-554. 2014.

(C) 2014 by The University of Chicago. All rights reserved.

1058-5893/2014/17505-0005\$15.00 DOI: $10.1086 / 675976$

\title{
IMPACT OF ENHANCED CAPACITY TO SCAVENGE REACTIVE OXYGEN SPECIES ON COLD TOLERANCE OF TOBACCO
}

\author{
Olga M. Grant, ${ }^{1, *}$ Donal P. Brennan,* Carmen D. Mellisho Salas, + and Philip J. Dix*
}

*Department of Biology, National University of Ireland, Maynooth, County Kildare, Ireland; and +Centro de Edafología y Biología Aplicada del Segura-Consejo Superior de Investigaciones Científicas, Campus Universitario de Espinardo, Murcia, Spain

\author{
Editor: Patrick S. Herendeen
}

\begin{abstract}
Premise of research. Reactive oxygen species (ROS) accumulate in plant tissues when the plant is exposed to stress, causing damage to cell structure and metabolism. Plants have a variety of mechanisms to prevent such damage, including a number of enzymes that scavenge ROS. The impact of specific enzymes, however, is as yet poorly understood.

Methodology. The impact on plant tolerance to cold stress of enzymes involved in scavenging ROS was explored by comparing transplastomic tobacco lines overexpressing genes encoding glutathione reductase (GR), dehydroascorbate reductase (DHAR), glutathione-S-transferase (GST), and manganese superoxide dismutase, singly or in pairwise combinations, with nontransformed (NT) tobacco.

Pivotal results. Chilling to $10^{\circ} \mathrm{C}$ resulted in less photoinhibition in lines overexpressing GR alone or in combination with GST, compared to NT tobacco, but more photoinhibition in lines overexpressing DHAR alone or in combination with GR. These differences were not, however, reflected in other indicators of stress. When chilled at $4^{\circ} \mathrm{C}$, all lines showed similar damage to NT, except under relatively high photosynthetically active radiation, in which case photoinhibition was reduced in all transplastomic lines compared to NT. Growth over several weeks in a greenhouse was inhibited in the transplastomic lines when the duration included transient cool air temperatures. When optimal air temperature was maintained, growth over a similar duration was equal in transplastomics and NT tobacco.
\end{abstract}

Conclusions. These experiments suggest a subtle interaction of enhanced ROS scavenging and tolerance of chilling stress.

Keywords: ascorbate-glutathione cycle, chlorophyll fluorescence, chilling tolerance, photoinhibition, stress imaging, superoxide dismutase.

\section{Introduction}

The chloroplast is a major source of reactive oxygen species (ROS) in leaves. A chain of events leads to the production of toxic ROS: superoxide $\left(\mathrm{O}_{2}^{--}\right)$, via spontaneous univalent electron transfer to molecular oxygen $\left(\mathrm{O}_{2}\right)$ from reduced components of the electron transport chain; hydrogen peroxide $\left(\mathrm{H}_{2} \mathrm{O}_{2}\right)$, as a result of enzymatic or spontaneous dismutation of $\mathrm{O}_{2}^{--}$; and the hydroxyl radical $\left({ }^{\circ} \mathrm{OH}\right)$, produced during reaction of $\mathrm{H}_{2} \mathrm{O}_{2}$ with transition metals $\left(\mathrm{Fe}^{2+}\right.$ or $\mathrm{Cu}^{+}$; Apel and Hirt 2004). A wide range of environmental stresses reduce a leaf's capacity to use photochemical energy, resulting in a reduction of photosynthesis. Light-dependent reduction of photosynthesis, when independent of developmental change, can be defined as photoinhibition (Long et al. 1994). The reduced capacity to use photochemical energy also results in

\footnotetext{
${ }^{1}$ Author for correspondence; current address: UCD Forestry, University College Dublin, Belfield, Dublin 4, Ireland; e-mail: olga .grant@ucd.ie.

Manuscript received July 2013; revised manuscript received January 2014; electronically published May 1, 2014.
}

excessive production of electrons in the chloroplast, enhancing production of ROS. Thus, environmental stress can lead to the accumulation of high levels of ROS, which react with proteins and lipids, causing damage to cellular structures. Damage to photosynthetic pigments and chloroplast structure under further exposure to light is irreversible (Larcher 1995) and inhibits leaf metabolism (Raven 2011).

Antioxidant defense mechanisms, both enzymatic and nonenzymatic, are involved in scavenging ROS in the chloroplast and in other cellular compartments. Superoxide dismutase (SOD) catalyzes the conversion of $\mathrm{O}_{2}^{--}$to $\mathrm{H}_{2} \mathrm{O}_{2}$. Ascorbate peroxidase (APX), glutathione peroxidase (GPX), and catalase (CAT) can each detoxify $\mathrm{H}_{2} \mathrm{O}_{2}$, but continued catalysis by APX requires regeneration of ascorbate and glutathione (Apel and Hirt 2004), which involves enzymes such as glutathione reductase (GR), dehydroascorbate reductase (DHAR), and monodehydroascorbate reductase (MDAR; Mittler et al. 2004). Since CAT is mainly associated with peroxisomes and GPX is cytosolic, APX is the primary catalyst for detoxifying $\mathrm{H}_{2} \mathrm{O}_{2}$ in the chloroplast (Apel and Hirt 2004). Monodehydroascorbate (MDA) is produced in this reaction, which then reacts with the reduced form of nicotinamide adenine dinu- 
cleotide (phosphate) $(\mathrm{NAD}(\mathrm{P}) \mathrm{H})$ to produce ascorbate-a reaction catalyzed by MDAR. MDA spontaneously produces dehydroascorbate (DHA), which can be reduced to ascorbate by DHAR, with the help of the reduced form of glutathione (GSH), which is oxidized to glutathione disulfide (GSSG). Finally, GR converts GSSG back to GSH. In plant chloroplasts, GR can simultaneously increase the ratio of reduced to oxidized glutathione and the total glutathione pool (Noctor et al. 1998). DHAR has been shown to be important for the maintenance of the ascorbate pool (Chen and Gallie 2005) and contributes to protection against oxidative stress in plant cells (Kwon et al. 2003). Some glutathione-S-transferase (GST) enzymes also exhibit GPX activity, directly functioning in detoxification during oxidative stress (Bartling et al. 1993). GST additionally attaches various toxic substances to glutathione, rendering them more easily removed from the cell (Burns et al. 2005).

One approach to understanding the role of different ROSscavenging enzymes in stress tolerance is to manipulate their level of activity. This laboratory has introduced genes encoding manganese SOD (MnSOD), DHAR, GR, and GST (with GPX activity) into the tobacco chloroplast genome (plastome) to obtain transplastomic lines, as has been previously described (Le Martret et al. 2011; Poage et al. 2011). Double transplastomic lines expressing DHAR and GR (DHAR + GR) or GR and GST (GR+GST) were also obtained (Le Martret et al. 2011). These combinations were of interest since DHAR and GR catalyze consecutive steps in the ascorbate-glutathione cycle in chloroplasts, and combining expression of GR and GST together could significantly influence glutathione homeostasis, further affecting the ROS-scavenging capacity of the chloroplast. As has already been described in detail (Le Martret et al. 2011; Poage et al. 2011), Southern blot analysis confirmed integration of the foreign genes, and Western blot analysis confirmed expression of the relevant transgenes in leaf tissue. The transplastomic lines showed the predicted altered activity of the relevant enzymes (threefold increase in SOD activity, up to threefold increase in DHAR activity, up to sixfold increase in GR activity, twofold increase in both GST and GPX as a result of insertion of the GST gene, up to fourfold increase in DHAR/GST, and fivefold increase in GR in the double transformants) and of the redox state of ascorbate and glutathione.

Research on abiotic stress tolerance of transgenics overexpressing ROS-scavenging enzymes has yielded conflicting results: some studies have shown a beneficial impact of the overexpression on tolerance to a wide range of types of abiotic stress (Mohamed et al. 2003; Badawi et al. 2004; Eltayeb et al. 2007), while others indicate a positive impact of overexpression in response to only some types of stress (Broadbent et al. 1995; Kwon et al. 2003; Le Martret et al. 2011). Several studies on different enzymes have found that overexpression of only some of those enzymes enhanced performance under a particular stress (Foyer et al. 1995; Payton et al. 2001; Faize et al. 2011; Le Martret et al. 2011; Poage et al. 2011). Photosynthetic processes are often the first physiological/metabolic processes to be inhibited by chilling temperature (Berry and Björkman 1980). It was hypothesized that for tobacco, the impact of chilling on photosynthetic processes would be reduced in plants with enhanced activity of the ascorbate-glutathione cycle enzymes or enhanced SOD activity. This pos- sibility was explored in our bank of transplastomic lines with increased expression of several enzymes associated with ROS scavenging.

\section{Material and Methods}

\section{Seed Germination and Seedling Growth Conditions}

Introduction of GR, DHAR, GST, DHAR + GR, and GR+GST genes into tobacco led to the production of several lines from each transformation (Le Martret et al. 2011; Poage et al. 2011). In transplastomic plants, targeted integration should result in different lines responding in a similar manner, because targeted integration eliminates the position effects associated with nuclear transformants. Moreover, the different lines showed the same phenotype under both optimal conditions and a range of stresses imposed on germinating seeds, young seedlings, and leaf discs (Le Martret et al. 2011). Therefore, to allow comparison of transplastomics of different genes within individual experiments, one line from each transformation was selected for this study: GR18, DHAR3, GST19, DHAR+GR2, and GST+GR15. Although our assessment of a single line follows precedents in the assessment of transplastomic plants for abiotic stress tolerance (Kumar et al. 2004; Craig et al. 2008), we do acknowledge that all direct DNA delivery methods have the potential for mutagenesis that could result in variation not directly related to the targeted integration and expression of the transgene-hence the inclusion of all three of the MnSOD lines that had been shown to exhibit phenotypic variation (Poage et al. 2011), in contrast to all the other lines used in this investigation (Le Martret et al. 2011).

Seeds from the various transplastomic lines and seeds from control nontransformed (NT) seed lines (all inbred selfed lines) were germinated on hormone-free Murashige and Skoog (1962) medium in petri dishes and incubated at $24^{\circ} \mathrm{C}$ for 1 wk. Germinated seedlings were then transferred to multipurpose compost in plug trays in a $25^{\circ} \mathrm{C}$ growth chamber with a 16L : 8D photoperiod (with photosynthetically active radiation of an average $139 \mu \mathrm{mol} \mathrm{m} \mathrm{m}^{-2} \mathrm{~s}^{-1}$ in light conditions) and relative humidity of $\sim 76 \%$ for a further week before being replanted in $10-\mathrm{cm}$ pots for growth chamber experiments or 1.5-L pots for the longer greenhouse experiments. A minimum of four replicate individual plants of each line were studied in each experiment.

\section{Leaf Physiology}

Dark-adapted chlorophyll a fluorescence variables were measured with a continuous excitation fluorometer (Handy PEA, Hansatech, King's Lynn, UK), following dark adaptation of $20 \mathrm{~min}$ on intact leaves or leaf discs. Both dark- and lightadapted fluorescence variables were captured with the imaging fluorometer. In this case, leaf discs were placed on the flat plate of the fluorometer and allowed to dark adapt for $20 \mathrm{~min}$ before images of $F_{\mathrm{V}} / F_{\mathrm{M}}$ (variable fluorescence/maximal fluorescence) were obtained; the leaves/discs were then allowed to light adapt for $30 \mathrm{~min}$ before images of light-adapted fluorescence variables were taken.

Photosynthetic assimilation was measured with an infrared gas analyzer (CIRAS 1, PP Systems, Amesbury, MA) under ambient light and air temperature. A carbon dioxide concen- 
tration of $390 \mu \mathrm{mol} \mathrm{m} \mathrm{m}^{-2} \mathrm{~s}^{-1}$ was maintained using an internal $\mathrm{CO}_{2}$ cylinder.

Thermal imaging (Snapshot, Infrared Solutions, Minneapolis) was used as a rapid means to determine variation in stomatal conductance (see Grant et al. 2012). The leaves of interest were kept flat by insertion in a nylon grid to ensure equal exposure to light. The lamina of each leaf of interest was outlined in the camera software to obtain the average temperature over the leaf (excluding the midvein). Wet and dry artificial reference leaves, consisting of black cotton material, were used in conjunction with leaf temperature to obtain an index of stomatal conductance, $I_{\mathrm{G}}$. As the plants grew, the grid was moved upward, resting on notches on wooden supports, so that the youngest fully expanded leaf was always measured.

Leaf discs $(1.5 \mathrm{~cm}$ diameter) were cut with a cork borer from the leaves of interest to determine electrolyte leakage.

\section{Leaf Biochemistry}

Fresh mass was determined for leaf discs of $1.5 \mathrm{~cm}$ diameter to estimate specific leaf area and to express pigment, malondialdehyde, and $\mathrm{H}_{2} \mathrm{O}_{2}$ content on a per fresh leaf mass basis. Discs used to assess malondialdehyde or $\mathrm{H}_{2} \mathrm{O}_{2}$ content were immediately frozen in liquid nitrogen and maintained at $-70^{\circ} \mathrm{C}$ until the respective assay. For pigment assays, the leaf discs were immediately soaked in methanol for $24 \mathrm{~h}$ and absorbance was read at 649, 664, and $470 \mathrm{~nm}$ (Lambda Scan 200, Bio-Tek Instruments, Potton, UK) to determine chlorophyll $a$, chlorophyll $b$, and carotene content (Lichtenthaler and Miehé 1997). Lipid peroxidation was assessed by monitoring the formation of malondialdehyde, by measuring absorbance following reaction with trichloroacetic acid and thiobarbituric acid (Du and Bramlage 1992). $\mathrm{H}_{2} \mathrm{O}_{2}$ content was measured spectrophotometrically after reaction with potassium iodide (Alexieva et al. 2001).

\section{Biomass and Plant Growth}

Plant height was measured at the start and end of the longerterm (more than $1 \mathrm{wk}$ ) experiments. Four plants per line (additional to the experimental plants) were destructively harvested to estimate initial leaf area and fresh and dry masses of leaves and stems; these measurements were conducted on the experimental plants at the end of the experiment. Leaf and stem fresh mass was determined after cutting off the plant at the base and separating leaves from stems. Leaf area of scanned images was determined in Adobe Photoshop. Dry mass was determined after drying at $80^{\circ} \mathrm{C}$ for $48 \mathrm{~h}$. Terminal buds were marked at the start of the experiment and leaf extension was measured at intervals thereafter.

\section{Meteorology}

Air temperature, relative humidity, and global radiation were monitored continuously (logged at half-hourly intervals) with a mini meteorological station (Datahog, Skye, Powys, UK) in the different growth chambers and the greenhouse. Photosynthetically active radiation (PAR) was estimated from global radiation (Jones 1992). Additionally, PAR was measured at each leaf of interest in the growth chamber experi- ments with a quantum meter (BQM, Apogee Instruments, Logan, UT).

\section{Experimental Design and Statistical Analysis}

A random block design was used for the greenhouse experiments and completely randomized designs were used for the growth chamber experiments. All experiments were analyzed with two-way ANOVA, with the two factors being tobacco line and stress treatment. Repeated-measures two-way ANOVA was used to analyze data collected from the same plants at intervals over time or where leaf discs were cut from the same plants and exposed to different treatments.

\section{Enzymes Involved in the Ascorbate-Glutathione Pathway}

Growth chamber experiments. In two experiments, whole plants in pots were subjected to cold treatment through manipulation of air temperature in growth chambers. In the first experiment, plant performance in a controlled-temperature $\left(25^{\circ} \mathrm{C}\right)$ growth chamber was compared with that in a cold $\left(10^{\circ} \mathrm{C}\right)$ growth chamber. In the second experiment, air temperature was reduced from $25^{\circ}$ to $4^{\circ} \mathrm{C}$, maintained at $4^{\circ} \mathrm{C}$ under light for $72 \mathrm{~h}$, and maintained at $4^{\circ} \mathrm{C}$ for a further 48 $\mathrm{h}$ in darkness, and then air temperature was increased back to $25^{\circ} \mathrm{C}$, at which point it was maintained for $48 \mathrm{~h}$ under light.

In a third experiment, cut leaf discs were exposed to different temperatures at controlled light levels by floating the discs on $10 \mathrm{~mL}$ of deionized water in test tubes and leaving the test tubes under the required PAR for $72 \mathrm{~h}$, using the illumination unit (44 high-power royal blue [450 nm] LED lamps) of an imaging fluorometer (IMAGING PAM, Maxi version, Walz, Effeltrich, Germany). The fluorometer was placed in a growth chamber, and air temperature in the chamber was set at either $25^{\circ} \mathrm{C}$ (control) or $4^{\circ} \mathrm{C}$. The experiment was conducted under two different PAR levels: 250 and $80 \mu \mathrm{mol} \mathrm{m}{ }^{-2} \mathrm{~s}^{-1}$.

Greenhouse experiments. Relatively long-term growth and physiological behavior of the transplastomic lines and NT tobacco were compared in a greenhouse under two sets of conditions: first, air temperature was not controlled and hence fluctuated, including transient low temperatures, and second, air temperature was maintained at $24^{\circ} \mathrm{C}$ throughout (control unit, HortiMaX Growing Solutions, Pijnacker, The Netherlands). Supplemental light (GroLux high-pressure 600-W sodium lamps, Osram Sylvania, Danvers, MA) was provided to maintain $15 \mathrm{~h}$ light at $>28 \mathrm{~W} \mathrm{~m}^{-2} \mathrm{~d}^{-1}$. Four replicates of each line in 1.5 -L pots were arranged in a greenhouse in groups of four plants so that every plant was under a lamp, ensuring equal exposure to light. Water use was determined weekly, gravimetrically, in parallel with monitoring of evaporative demand using an evaporimeter (Evaposensor, Skye, Powys, UK); irrigation was applied every $2-3 \mathrm{~d}$ via pressure-compensated drippers, according to estimated water use in that duration (Grant et al. 2012), to replace $100 \%$ of water used in transpiration.

\section{Superoxide Dismutase}

Whole plants in pots were subjected to cold treatment by manipulating the air temperature in a growth chamber. Air temperature was reduced from $25^{\circ}$ to $4^{\circ} \mathrm{C}$ and maintained at 
$4^{\circ} \mathrm{C}$ for $72 \mathrm{~h}$ before being returned to $25^{\circ} \mathrm{C}$. The same photoperiod used during seedling growth was maintained through the experiment.

\section{Results}

\section{Growth Chamber Experiments}

Enzymes involved in the ascorbate-glutathione pathway. The ratio of variable to maximal fluorescence $\left(F_{\mathrm{V}} / F_{\mathrm{M}}\right)$, which indicates maximal photochemical capacity of photosystem II (PSII), was reduced and initial fluorescence $\left(F_{\mathrm{o}}\right)$ of the fourth leaf of 6-wkold tobacco seedlings increased only $1 \mathrm{~d}$ after transfer to a lowtemperature $\left(10^{\circ} \mathrm{C}\right)$ environment, indicating photoinhibition (Havaux 1992). Transplastomic lines behaved in the same manner as nontransformed plants until $2 \mathrm{wk}$ later. At that point, $F_{\mathrm{V}} / F_{\mathrm{M}}$ well below the optimum of $\sim 0.84$ indicated photoinhibition in all plants in the cold, but higher $F_{\mathrm{V}} / F_{\mathrm{M}}$ (fig. $1 a$ ) and lower $F_{\mathrm{o}}$ (fig. $1 b)$ in GR plants compared to NT plants indicated better cold tolerance in those plants with enhanced GR activity. GR was the only line that did not show an increase in $F_{\mathrm{o}}$ in the cold temperature compared to the control temperature. DHAR and DHAR+GR plants, however, were more photoinhibited in the cold than NT, showing lower $F_{\mathrm{V}} / F_{\mathrm{M}}$ and higher $F_{\mathrm{o}}$. DHAR and DHAR + GR also showed significantly lower $F_{\mathrm{V}} / F_{\mathrm{M}}$ and higher $F_{\mathrm{o}}$ than GST or GST+GR. Leaves of DHAR + GR showed significantly lower $F_{\mathrm{V}} / F_{\mathrm{M}}$ than NT even under control conditions. Modulated chlorophyll $a$ fluorescence imaging showed variation in the quantum yield of nonregulated energy dissipation $(Y[N O])$. The increase due to cold in $Y(\mathrm{NO})$ was greatest for NT and least for GST+GR (fig. 1c). However, the effective yield of PSII and electron transport rate were equally reduced by the cold treatment across all lines (data not shown). No difference between lines was detected in coefficients of photochemical or nonphotochemical quenching.

Photosynthetic assimilation rate, chlorophyll and carotene contents, electrolyte leakage, and lipid peroxidation (measured as malondialdehyde content) were equally affected by cold in all the transplastomics and NT. Shoot (stem + leaves) dry mass was similarly reduced by cold in all transplastomics and NT (table 1). Shoot height was least reduced by cold in DHAR. The length of the longest leaf was most reduced by cold in NT but was also reduced in GR (table 1).

Three weeks after the onset of cold treatment, all lines were severely photoinhibited, with an average $F_{\mathrm{V}} / F_{\mathrm{M}}$ of 0.48 , and there was no longer any difference between lines. On returning the plants at this stage to control temperatures, $F_{\mathrm{V}} / F_{\mathrm{M}}$ recovered to prestress levels within $3 \mathrm{~d}$, indicating no irreversible damage at $10^{\circ} \mathrm{C}$.

In a separate experiment, air temperature in the growth chamber was reduced from the control to $4^{\circ} \mathrm{C}$ to impose a more severe stress, which might lead to greater ROS production. $F_{\mathrm{V}} / F_{\mathrm{M}}$ fell (fig. $2 a$ ), as did chlorophyll content (by $22 \%$ ), and electrolyte leakage increased (from $16 \%$ to $47 \%$ ) in leaves of all plants after $48 \mathrm{~h}$ of cold treatment, indicating stress. Another $24 \mathrm{~h}$ later, $F_{\mathrm{v}} / F_{\mathrm{M}}$ had fallen further. The lights in the growth chamber were then turned off, preventing further photoinhibition. There was, however, no recovery of $F_{\mathrm{V}} / F_{\mathrm{M}}$ following $48 \mathrm{~h}$ of darkness. Air temperature in the growth chamber was then increased back to $25^{\circ} \mathrm{C}$, but $2 \mathrm{~d}$ later there was
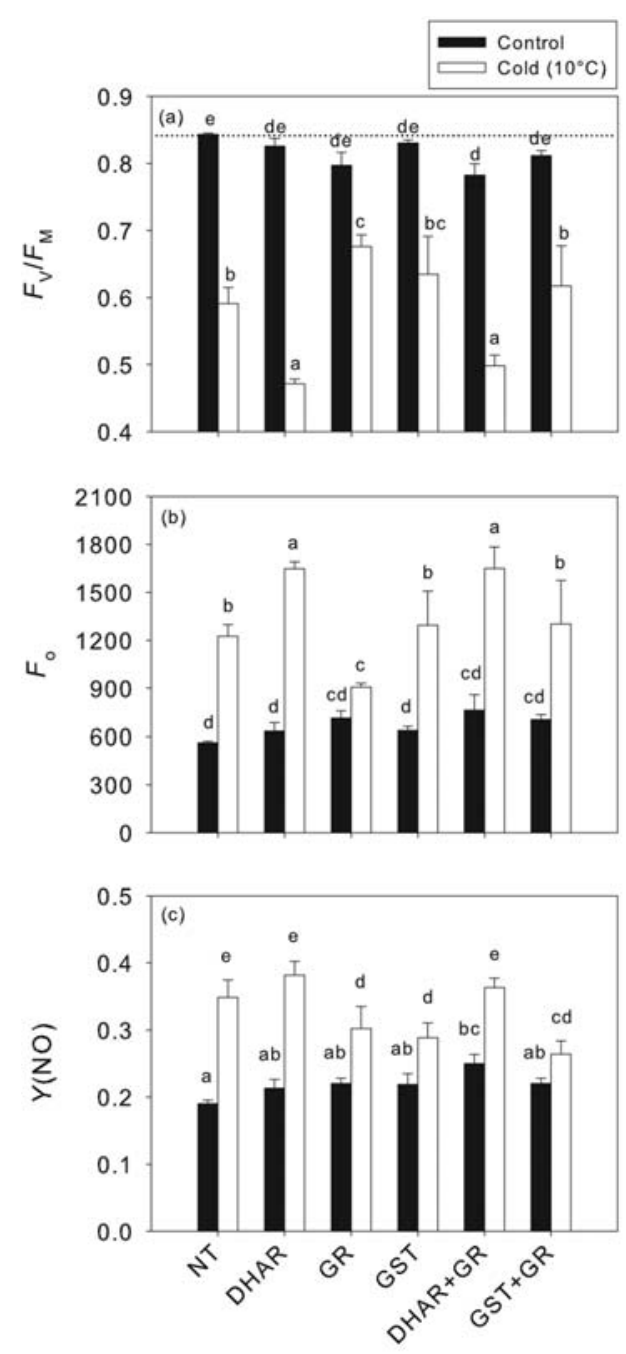

Line

Fig. 1 Ratio of variable to maximal chlorophyll fluorescence $\left(F_{\mathrm{V}} / F_{\mathrm{M}} ; a\right)$, initial chlorophyll fluorescence $\left(F_{\mathrm{o}} ; b\right)$, and quantum yield of nonregulated energy dissipation $(\mathrm{Y}[\mathrm{NO}] ; c)$ in leaves of nontransformed (NT) and different transplastomic lines (DHAR = dehydroascorbate reductase, GR = glutathione reductase, GST = glutathioneS-transferase) of tobacco following $2 \mathrm{wk}$ in either control $\left(25^{\circ} \mathrm{C}\right)$ or cold $\left(10^{\circ} \mathrm{C}\right)$ treatments; whole plants were subjected to these conditions in growth chambers. Columns represent means $+\mathrm{SE}, n=4$. Within a graph, columns with different letters are significantly different from each other (least significant difference following two-way ANOVA, $P<0.05)$. The dotted line in $a$ indicates optimal $F_{\mathrm{V}} / F_{\mathrm{M}}$.

still no recovery of $F_{\mathrm{V}} / F_{\mathrm{M}}$. Therefore, in this experiment, there is strong evidence that the photosynthetic apparatus was damaged, suggestive of ROS accumulation. $\mathrm{H}_{2} \mathrm{O}_{2}$ content of leaves, however, showed a substantial increase only late in the experiment (fig. $2 b$ ). The response to the cold stress in $F_{\mathrm{V}} / F_{\mathrm{M}}$, electrolyte leakage, and chlorophyll content was uniform across NT and transplastomic lines.

Additional experiments were conducted in which the lamp of the chlorophyll imaging fluorometer was used to provide a 


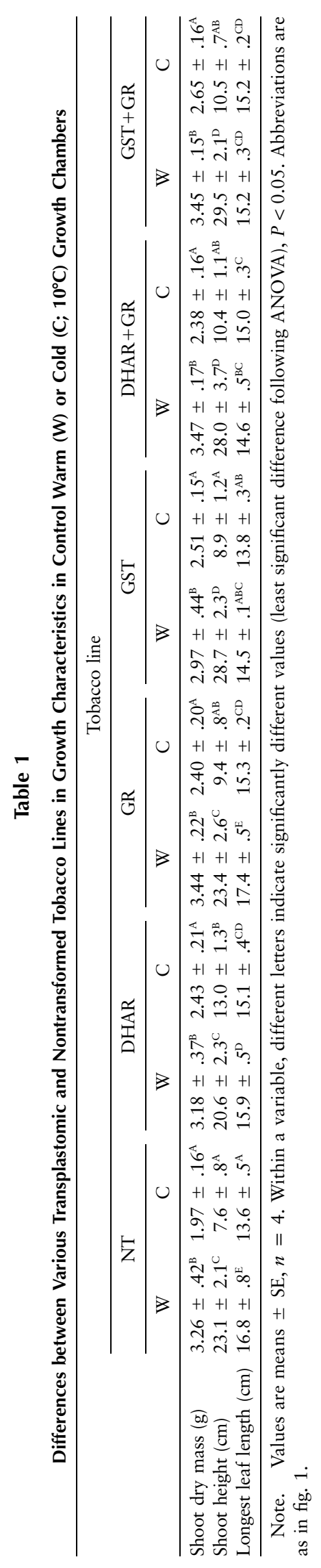



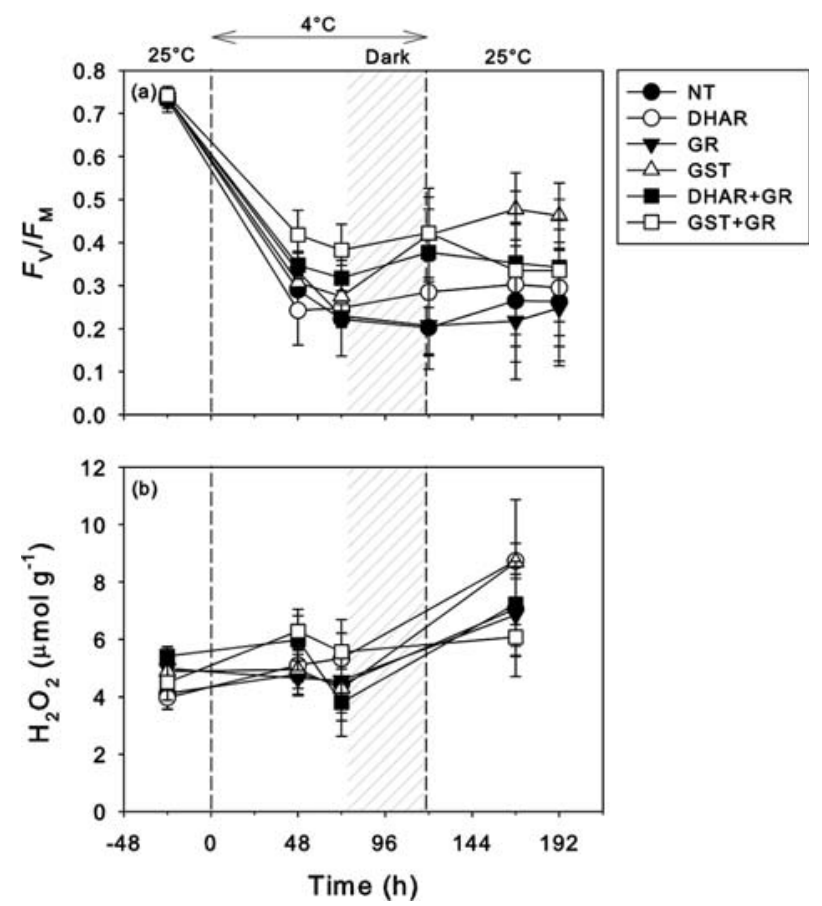

Fig. 2 Ratio of variable to maximal chlorophyll fluorescence $\left(F_{\mathrm{V}} / F_{\mathrm{M}} ; a\right)$ and hydrogen peroxide $\left(\mathrm{H}_{2} \mathrm{O}_{2}\right)$ content $(b)$ in leaves of nontransformed and different transplastomic lines of tobacco while air temperature was reduced from $25^{\circ}$ to $4^{\circ} \mathrm{C}$ and then increased again; whole plants were subjected to these conditions in a growth chamber. Symbols represent means $\pm \mathrm{SE}, n=4$. Abbreviations are as in fig. 1.

set level of PAR over leaf discs floated on water for $72 \mathrm{~h}$. At PAR of $250 \mu \mathrm{mol} \mathrm{m}{ }^{-2} \mathrm{~s}^{-1}, F_{\mathrm{V}} / F_{\mathrm{M}}$ was drastically reduced in discs exposed to $4^{\circ} \mathrm{C}$ compared to $25^{\circ} \mathrm{C}$ (fig. 3), indicating photoinhibition at $4^{\circ} \mathrm{C}$. NT discs, however, were significantly more damaged than discs from the transformant lines. There was no significant difference in $F_{\mathrm{V}} / F_{\mathrm{M}}$ between the different transplastomic lines. When the experiment was repeated at low PAR $\left(80 \mu \mathrm{mol} \mathrm{m}^{-2} \mathrm{~s}^{-1}\right), F_{\mathrm{V}} / F_{\mathrm{M}}$ was reduced at $4^{\circ} \mathrm{C}$ compared to $25^{\circ} \mathrm{C}$ (fig. 3 ) but far less severely than at the higher PAR. At lower PAR, no difference in $F_{\mathrm{V}} / F_{\mathrm{M}}$ was detected between transplastomics and NT.

Superoxide dismutase. After $48 \mathrm{~h}$ of cold treatment, $F_{\mathrm{V}} / F_{\mathrm{M}}$ fell equally in the SOD transformants and the NT tobacco (data not shown). After $72 \mathrm{~h}$ of cold treatment, $\mathrm{H}_{2} \mathrm{O}_{2}$ content in leaves of one SOD line, SOD6, was more than twice that in NT leaves (table 2). $\mathrm{H}_{2} \mathrm{O}_{2}$ content in the leaves of the other two SOD lines, however, was not significantly higher than in the NT leaves.

\section{Greenhouse Experiments}

In the first greenhouse experiment, air temperature fluctuated considerably over the $8 \mathrm{wk}$ (fig. $4 a$ ). This experiment was in an unheated greenhouse over winter, with air temperatures sometimes falling to below $5^{\circ} \mathrm{C}$ at night. PAR also fluctuated, with maximum daily PAR often reaching $250 \mu \mathrm{mol} \mathrm{m} \mathrm{m}^{-2} \mathrm{~s}^{-1}$ (fig. 4b).
In the experiment in which air temperature was not controlled, in the third week, the transplastomic lines showed lower specific leaf area (fig. $4 c$ ), lower total chlorophyll content (fig. $4 d$ ), and, with the exception of DHAR + GR, lower carotene content (fig. $4 e$ ) compared to NT tobacco. Such differences were not seen in discs taken from the same (old) leaves 5 wk later, at which point pigment contents had fallen and

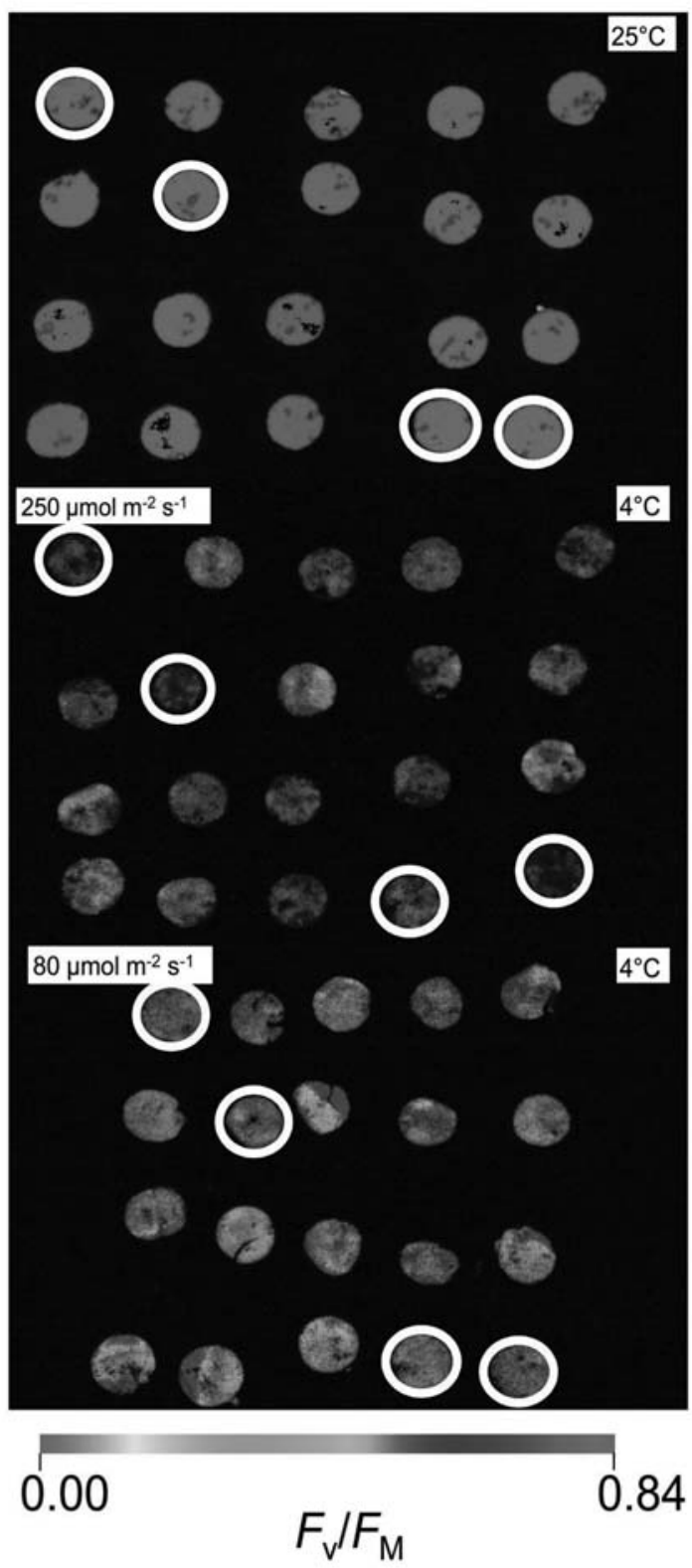

Fig. 3 Ratio of variable to maximal chlorophyll fluorescence $\left(F_{\mathrm{V}} / F_{\mathrm{M}}\right)$ in leaf discs following $72 \mathrm{~h}$ at $25^{\circ} \mathrm{C}($ top $)$ or $4^{\circ} \mathrm{C}$ (middle, bottom) under photosynthetically active radiation of $250 \mu \mathrm{mol} \mathrm{m}^{-2}$ $\mathrm{s}^{-1}$ or $80 \mu \mathrm{mol} \mathrm{m} \mathrm{m}^{-2} \mathrm{~s}^{-1}$. Detached leaf discs were subjected to these conditions in a growth chamber. Discs from nontransformed tobacco are outlined with white circles. 
Table 2

Hydrogen Peroxide $\left(\mathrm{H}_{2} \mathrm{O}_{2}\right)$ Content in Leaves of Nontransformed (NT) or Transplastomic Tobacco Lines during Cold Treatment $\left(4^{\circ} \mathrm{C}\right)$

\begin{tabular}{lc}
\hline Tobacco line & $\mathrm{H}_{2} \mathrm{O}_{2}$ content $\left(\mu \mathrm{mol} \mathrm{g}^{-1}\right)$ \\
\hline NT & $9.16 \pm 1.68$ \\
SOD1 & $12.86 \pm 3.17$ \\
SOD2 & $13.94 \pm 2.36$ \\
SOD6 & $23.15 \pm 3.08^{*}$ \\
\hline
\end{tabular}

Note. Data are means \pm SE, $n=6$. The asterisk indicates a significantly different mean to all the others (least significant difference following two-way ANOVA), $P<0.05$. Whole plants were grown in the growth chamber. $\mathrm{SOD}=$ superoxide dismutase.

specific leaf area increased (fig. $4 c-4 e$ ), nor in young (new) leaf tissue taken at that stage from leaves that developed during the experiment (fig. $4 c-4 e$ ). In the third week of treatments, below optimal $F_{\mathrm{V}} / F_{\mathrm{M}}$ indicated photoinhibition (fig. $4 f$ ), which was more severe in all transplastomic lines than in NT. Later in the experiment, however, there was no longer any difference in $F_{\mathrm{V}} / F_{\mathrm{M}}$ between $\mathrm{NT}$ and the transplastomic lines (average $0.77 \pm 0.01$ in week 8 ).

The net increase in leaf area during the experiment (some older leaves senesced and disintegrated) was greater in NT than in any transplastomic line (table 3). The increase in stem fresh mass was also greater in NT than in any transplastomic line. Dry shoot mass was reduced in DHAR and DHAR + GR compared to NT: this is due to a greater shoot mass at the end of the experiment rather than any difference at the beginning and largely relates to differences in the mass of that part of the stem and those leaves that existed prior to the imposition of treatments (old leaf and stem mass; table 3), suggesting that biomass gain was less in DHAR and DHAR+GR compared to NT early in the experiment. $\mathrm{H}_{2} \mathrm{O}_{2}$ content (on average 5.94 $\mu \mathrm{mol} \mathrm{g}{ }^{-1}$ ) was similar in the different lines and in NT tobacco.

In the second long-term greenhouse experiment, temperature in the greenhouse was maintained at an optimal level $\left(24^{\circ} \mathrm{C}\right)$. In this case, no differences in the above variables were found between the transplastomic lines and NT tobacco. The $I_{\mathrm{G}}$, photosynthetic assimilation, and malondialdehyde content did not differ significantly between NT and transplastomic tobacco in either experiment (fluctuating or constant air temperature).

\section{Discussion}

\section{Enzymes Involved in the Ascorbate-Glutathione Pathway}

Short-term responses. The first chilling experiment with whole plants indicated improved cold tolerance in those plants with enhanced GR activity, although some photoinhibition even in GR and GST+GR tobacco transplastomics was indicated by below optimal $F_{\mathrm{V}} / F_{\mathrm{M}}(\sim 0.84$; Maxwell and Johnson $2000)$. Enhanced GR activity as a result of chloroplast transformation in cotton also improved photosynthetic tolerance of chilling at $10^{\circ} \mathrm{C}$ (Payton et al. 2001). Expression of GR in the chloroplasts of poplar led to decreased sensitivity to exposure to high radiation and to methyl viologen (Foyer et al. 1995); glutathione content in the leaves increased, as did the proportion in the reduced state (GSH). In this study, the GR line assessed also exhibited increased total glutathione content in leaves (Poage et al. 2011). Foyer et al. (1995) found that the increased GSH led to an increased ascorbate pool and suggested that their results were evidence of the importance of GSH-mediated ascorbate regeneration via the ascorbate-GSH cycle. Suppression of the enzymes involved in the alternative regeneration cycles during chilling may increase the relevance of GSH-mediated ascorbate regeneration, where GSH availability has been enhanced as a result of the GR transformation.

In this study, enhanced expression of DHAR increased susceptibility to photoinhibition, and where increased DHAR and GR activity were combined, the impact of DHAR appeared to override any beneficial impact of enhanced GR expression. This may be because the ratio of reduced glutathione to oxidized glutathione was not increased compared to NT in the DHAR+GR transplastomics (Poage et al. 2011), preventing the direct impact of enhanced GR activity on regeneration of ascorbate suggested by Foyer et al. (1995), as outlined above. In addition to low $F_{\mathrm{V}} / F_{\mathrm{M}}$ and high $F_{\mathrm{o}}, Y(\mathrm{NO})$ was relatively high in cold-exposed leaves of DHAR and DHAR+GR, with high $Y(\mathrm{NO})$ indicating downregulation of both photochemical energy conversion and protective regulatory mechanisms (Kramer et al. 2004). This impact of enhanced DHAR activity contrasts with results for transgenic tobacco expressing a human DHAR, in which case tolerance of less severe cold $\left(15^{\circ} \mathrm{C}\right)$ was enhanced compared to NT (Kwon et al. 2003). In this experiment, leaves of DHAR + GR showed significantly lower $F_{\mathrm{V}} / F_{\mathrm{M}}$ than leaves of NT even under control conditions, suggesting slightly lowered photochemical capacity at optimal air temperature. Despite greater photoinhibition in DHAR than NT, plant height was least reduced by cold in DHAR. Research in which nuclear-encoded DHAR was expressed in tobacco chloroplasts also found that the height of transgenic plants was less reduced by mild cold stress $\left(15^{\circ} \mathrm{C}\right)$ compared to NT, but unlike in this study, in that case DHAR tobacco also maintained greater shoot dry mass and chlorophyll content (Kwon et al. 2003). The results of this study suggest that the differences in photoinhibition had little impact on photosynthesis or growth, and other measures of stress (electrolyte leakage and lipid peroxidation) showed no difference between any of the transplastomics and NT. This may be because effects of enhanced activity on photoinhibitory damage as a result of cold temperature were transitory, since eventually $F_{\mathrm{V}} / F_{\mathrm{M}}$ fell to similarly low values in all plants. Recovery of $F_{\mathrm{V}} / F_{\mathrm{M}}$ to prestress levels when plants were returned to the control temperature indicates that the stress induced by this chilling treatment was relatively mild, perhaps insufficient to result in a substantial benefit of enhanced ROS scavenging. However, a more severe chilling stress $\left(4^{\circ} \mathrm{C}\right)$, also with whole plants, that led to a clear and irreversible impact on leaf photochemistry also did not produce any differences between transgenic and NT tobacco in terms of chlorophyll fluorescence, electrolyte leakage, or chlorophyll content.

$\mathrm{H}_{2} \mathrm{O}_{2}$ content following chilling at $4^{\circ} \mathrm{C}$ showed a rise, fall, and then another rise, as has been reported previously in strawberry leaves (Yong et al. 2008); it seems that production of $\mathrm{H}_{2} \mathrm{O}_{2}$ was delayed relative to stress exposure. Thus, the photoinhibition and loss of chlorophyll content and increase in electrolyte leakage detected prior to the increase in $\mathrm{H}_{2} \mathrm{O}_{2}$ con- 

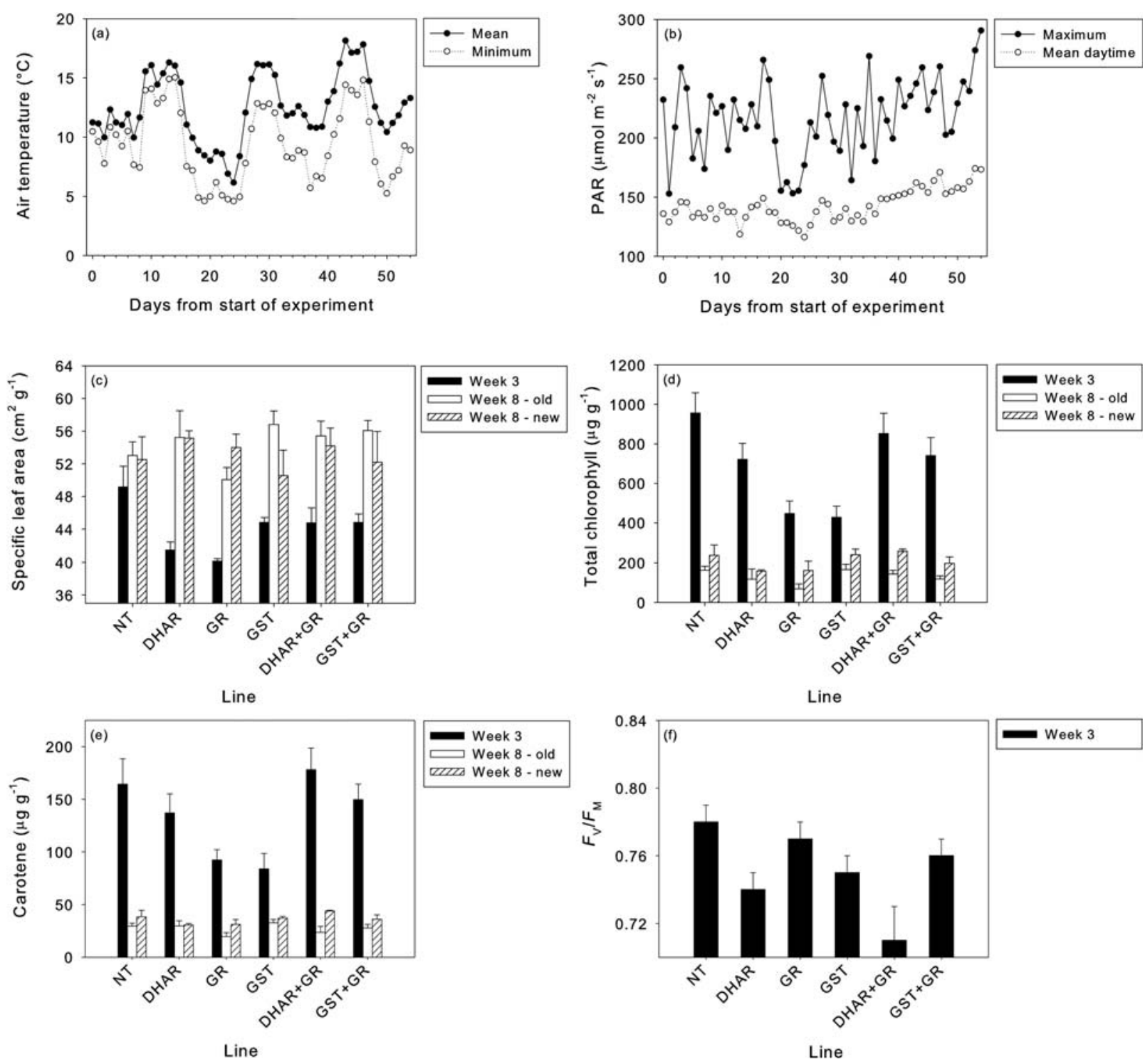

Fig. 4 Air temperature $(a)$ and photosynthetically active radiation (PAR; $b$ ) during an experiment in an unheated greenhouse, in which nontransformed and transformed tobacco were grown for $8 \mathrm{wk}$, and the specific leaf area $(c)$, total chlorophyll content $(d)$, carotene content $(e)$, and ratio of variable to maximal chlorophyll fluorescence $\left(F_{\mathrm{v}} / F_{\mathrm{M}} ; f\right)$ of their leaves. Columns represent means $+\mathrm{SE} ; n=4$. Whole plants were grown in this greenhouse experiment. Abbreviations are as in fig. 1.

tent may relate not to ROS-induced damage but rather to reduced photosynthetic rate and chlorophyll production and changes in membrane configuration due to chilling-induced lipid-phase changes (Leshem 1992). The lack of difference between transplastomics and NT conflicts with earlier research (Le Martret et al. 2011) with cut leaf discs of some of the same tobacco lines, in which tolerance to chilling at $8^{\circ} \mathrm{C}$ for $72 \mathrm{~h}$ was slightly increased in discs of DHAR and GST and more substantially increased in discs of GST $+\mathrm{GR}$ and DHAR + GR compared to NT. On the other hand, at $4^{\circ} \mathrm{C}$ and PAR of $1000 \mu \mathrm{mol} \mathrm{m}^{-2} \mathrm{~s}^{-1}$, reduced photoinhibition as a result of GR overexpression in poplar was detected only when expression was extremely high (a thousandfold increase com- pared to NT) and not at expression levels (a two- to 10-fold increase) more similar to those measured in the lines studied here (Foyer et al. 1995).

Photoinhibition in the cold is known to be dependent on light exposure (Allen and Ort 2001). PAR could not be controlled in the growth chambers and, moreover, was not uniform through the chamber, resulting in variability of exposure within a line; in addition, intact tobacco leaves are not flat, further adding to variability of irradiance. For this reason, an additional experiment was undertaken using flat leaf discs rather than whole plants. Although enhanced scavenging capacity did not prevent photoinhibition in the cut leaf discs at $4^{\circ} \mathrm{C}$ and PAR of $250 \mu \mathrm{mol} \mathrm{m}{ }^{-2} \mathrm{~s}^{-1}\left(F_{\mathrm{V}} / F_{\mathrm{M}}\right.$ fell drastically in all 
Table 3

\begin{tabular}{|c|c|c|c|c|c|c|c|}
\hline & \multicolumn{7}{|c|}{ Tobacco line } \\
\hline \multicolumn{8}{|l|}{ Increase over experiment: } \\
\hline Leaf area $\left(\mathrm{cm}^{2}\right)$ & $778 \pm 211^{\mathrm{B}}$ & $281 \pm 174^{\mathrm{A}}$ & 346 & $\pm 183^{\mathrm{A}}$ & $260 \pm 66^{\mathrm{A}}$ & $373 \pm 85^{\mathrm{A}}$ & $27 \pm 322^{\mathrm{A}}$ \\
\hline Shoot & $21.57 \pm 1.08^{\mathrm{C}}$ & $18.26 \pm .91^{\mathrm{AB}}$ & 19.97 & $\pm 1.29^{\mathrm{BC}}$ & $19.02 \pm 1.32^{\mathrm{BC}}$ & $18.53 \pm 1.09^{\mathrm{A}}$ & $20.12 \pm 1.20^{\mathrm{BC}}$ \\
\hline Old leaf & $6.50 \pm .16^{\mathrm{C}}$ & $4.90 \pm .41^{\mathrm{AB}}$ & 6.69 & $\pm .61^{\mathrm{BC}}$ & $5.56 \pm .32^{\mathrm{AB}}$ & $5.05 \pm .29^{\mathrm{A}}$ & $4.39 \pm .42^{\mathrm{A}}$ \\
\hline Old stem & $8.16 \pm .83^{\mathrm{B}}$ & $5.98 \pm .39^{\mathrm{AB}}$ & 7.12 & $\pm 1.28^{\mathrm{AB}}$ & $7.83 \pm .68^{\mathrm{B}}$ & $5.81 \pm .24^{\mathrm{A}}$ & $8.02 \pm .85^{\mathrm{B}}$ \\
\hline
\end{tabular}

Note. Values are means $\pm \mathrm{SE}, n=4$. Within a variable, different letters indicate significant differences between tobacco lines (least significant difference following ANOVA), $P<0.05$. Old leaves/stem refer to leaves and the stem below the new bud marked at the start of the experiment, that is, they were present prior to the initial growth measurements. Abbreviations are as in fig. 1.

leaf discs), it did reduce it. Reduced impact of this temperature in combination with very high PAR $\left(1000 \mu \mathrm{mol} \mathrm{m}^{-2} \mathrm{~s}^{-1}\right)$ on photosynthetic rate has previously been observed in intact leaves of tobacco expressing an introduced GPX gene (Yoshimura et al. 2004). In this study, the impact of chilling at $4^{\circ} \mathrm{C}$ was clearly dependent on PAR, with no difference between transplastomics and NT being detected at lower PAR exposure.

Long-term impacts of overexpression. The two greenhouse experiments offer the possibility of examining the impact of overexpression on plant physiology and growth in the relatively long term-something that has rarely been investigated. Transplastomics behaved differently from NT in the first of these experiments, which appears to relate to increased photoinhibition during cool conditions early in that study. Variation in specific leaf area and pigment content over time in the experiment relate to aging but also probably to fluctuating air temperatures. In particular, below-optimal $F_{\mathrm{V}} / F_{\mathrm{M}}$ in the third week of treatments, indicating photoinhibition, probably relates to low greenhouse temperatures in combination with occasionally relatively high maximum daytime PAR around that time. Lower $F_{\mathrm{v}} / F_{\mathrm{M}}$ at this stage in all transplastomic lines than in NT suggests a negative impact of the inserted genes on leaf physiology in these conditions. Biomass differences between tobacco lines, even though dependent on productivity through the entire experiment, may also relate to the photoinhibition detected early in the experiment: limited biomass production in DHAR and DHAR + GR is suggestive of an impact of cold, given the greater photoinhibition of these lines in the shortterm $10^{\circ} \mathrm{C}$ experiment. This contrasts with the reduced susceptibility of the transplastomics to photoinhibition at $4^{\circ} \mathrm{C}$ under relatively high PAR (in the leaf disc experiment) but for DHAR is consistent with the greater photoinhibition seen in this line in the $10^{\circ} \mathrm{C}$ experiment, suggesting a negative impact of enhanced DHAR activity during mild chilling. It has been found that $\mathrm{H}_{2} \mathrm{O}_{2}$ is necessary to acclimate to excess electron excitation (Karpinski et al. 1999), and treating maize seedlings with $\mathrm{H}_{2} \mathrm{O}_{2}$ increased protection against chilling in darkness (Prasad et al. 1994). Thus, lines with enhanced scavenging of $\mathrm{H}_{2} \mathrm{O}_{2}$ could be at a disadvantage during such chilling as occurred, in particular, in the cool greenhouse. A detrimental effect of overexpression has been detected in some other stud-
ies-GR overexpression was seen to increase sensitivity to paraquat (Poage et al. 2011), while insertion of MnSOD resulted in increased sensitivity to $\mathrm{H}_{2} \mathrm{O}_{2}$ (Mancini et al. 2006). The lack of differences between DHAR and NT in pigment content, photosynthetic assimilation, and stomatal conductance in these two experiments contrasts with other research over similar-duration experiments, in which insertion of a DHAR gene led to a delay in leaf senescence, higher chlorophyll content and photosynthetic rate, and more open stomata (Chen and Gallie 2005, 2006). PAR in those experiments was, however, far higher (averaging more than $750 \mu \mathrm{mol} \mathrm{m}^{-2} \mathrm{~s}^{-1}$ ) and therefore more likely to lead to photoinhibition. The lack of differentiation between transplastomic and NT tobacco when air temperature was maintained constant and optimal further suggests that the differences seen in the first long-term greenhouse experiment related to response to temperature.

\section{Superoxide Dismutase}

Since SOD acts as the first line of defense against ROS production, it was considered that responses to stress of lines with enhanced SOD activity may differ from those with enhanced activity of enzymes involved in the ascorbate-glutathione pathway. The $F_{\mathrm{V}} / F_{\mathrm{M}}$ fell during cold treatment in SOD transplastomics and NT tobacco alike. The impact of cold treatment on photosynthetic rates of cotton was similarly unaffected by overexpression of a chloroplast-targeted MnSOD (Payton et al. 1997) —or at least when the treatment duration was greater than $1 \mathrm{~h}$ (Payton et al. 2001), as was the case in this study. High $\mathrm{H}_{2} \mathrm{O}_{2}$ content in leaves of one SOD line, SOD6, in this research could be the result of SOD removing $\mathrm{O}_{2}^{--}$via production of $\mathrm{H}_{2} \mathrm{O}_{2}$. If this is the case, the impact was not, however, seen in the other two SOD lines. Variation between lines of a particular transgenic has been reported previously. For example, of three poplar lines into which $\gamma$-glutamylcysteine synthetase (required for production of glutathione) had been introduced, one showed a reduction in $F_{\mathrm{v}} / F_{\mathrm{M}}$ compared to NT, while another showed increased photosynthetic assimilation and $F_{\mathrm{V}} / F_{\mathrm{M}}$ compared to NT, and there was also growth variation between the three (Herschbach et al. 2010). Similarly, the impact on oxidative and ozone stress tolerance of inserting 
GR genes into tobacco has been found to vary between lines (Broadbent et al. 1995). Plastid (in contrast to nuclear) transformation, however, proceeds through homologous recombination, that is, targeted integration, so less interline variation would be expected. Our results with SOD transplastomics, however, indicate that in fact variation can exist between transplastomic lines, and therefore our conclusions with respect to genes involved in the ascorbate-glutathione cycle should be validated with the use of more lines resulting from each transformation.

Enhanced tolerance of the same lines studied here has been described with respect to oxidative stress (imposed by floating leaf discs on paraquat) and UVB (imposed by floating leaf discs under very high UVB). Contrasting results in this study (with ascorbate-glutathione cycle transplastomics at $4^{\circ} \mathrm{C}$ ) between measurements on intact leaves and leaves floated on water point to a possible cause of variation between this and previous studies; that is, the previous work was entirely undertaken with leaf discs, while this study with the SOD lines relates to whole plants.

Although this study provides evidence of short-term variation between the SOD lines in response to cold, there is no evidence that such variation is sustained. In conjunction with the existence of transient differences in response to cold in DHAR and DHAR + GR compared to NT tobacco (at $10^{\circ} \mathrm{C}$ ), this suggests a transient nature of the impact of the insertion of genes involved in ROS scavenging, although reduced growth rate in transplastomic lines compared to NT in the long-term experiment during cool air temperatures suggests that transient impacts on photosynthesis can have significant longer-term effects.

\section{Conclusion}

In conclusion, the impact of the genes studied here on tolerance of low temperatures appears to be subtle. ROS production is highly dependent on incident PAR, and in particular, the $4^{\circ} \mathrm{C}$ experiment at different light intensities suggests that the impact of the overexpression of the ROS-scavenging enzymes we studied may be dependent on the interaction of light and cold stress.

\section{Acknowledgments}

O. M. Grant was funded by a Marie Curie Intra-European Fellowship (grant 252196, IMaging of Plant Responses to Environmental StresS). We are very grateful to M. Jansen (University College Cork) for lending the imaging fluorometer and for advising as to its use. We thank H. G. Jones (University of Dundee) for the loan of the thermal camera, gas analyzer, mini meteorological station, and dark-adaptation leaf clips. C. J. Atkinson (East Malling Research) provided the Evaposensor. We are also grateful for anonymous feedback during the review process.

\section{Literature Cited}

Alexieva V, I Sergiev, S Mapelli, E Karanov 2001 The effect of drought and ultraviolet radiation on growth and stress markers in pea and wheat. Plant Cell Environ 24:1337-1344.

Allen DJ, DR Ort 2001 Impacts of chilling temperatures on photosynthesis in warm-climate plants. Trends Plant Sci 6:36-42.

Apel K, H Hirt 2004 Reactive oxygen species: metabolism, oxidative stress, and signal transduction. Annu Rev Plant Biol 55:373-399.

Badawi GH, N Kawano, Y Yamauchi, E Shimeda, R Sasaki, A Kubo, $\mathrm{K}$ Tanaka 2004 Over-expression of ascorbate peroxidase in tobacco chloroplasts enhances the tolerance to salt stress and water deficit. Physiol Plant 121:231-238.

Bartling D, R Radzio, U Steiner, EW Weiler 1993 A glutathione-Stransferase with glutathione-peroxidase activity from Arabidopsis thaliana: molecular cloning and functional characterization. Eur J Biochem 216:579-586.

Berry J, O Björkman 1980 Photosynthetic response and adaptation to temperature in higher plants. Annu Rev Plant Physiol 31:491543.

Broadbent P, GP Creissen, B Kular, AR Wellburn, P Mullineaux 1995 Oxidative stress responses in transgenic tobacco containing altered levels of glutathione reductase activity. Plant J 8:247-255.

Burns C, R Geraghty, C Neville, A Murphy, K Kavanagh, S Doyle 2005 Identification, cloning, and functional expression of three glutathione transferase genes from Aspergillus fumigatus. Funct Genet Biol 42:319-327.

Chen Z, DR Gallie 2005 Increasing tolerance to ozone by elevating foliar ascorbic acid confers greater protection against ozone than does increasing avoidance. Plant Physiol 138:1673-1689.

2006 Dehydroascorbate reductase affects leaf growth, development, and function. Plant Physiol 142:775-787.

Craig W, P Lenzi, N Scotti, M De Palma, P Saggese, V Carbone, N McGrath Curran, et al 2008 Transplastomic tobacco plants ex- pressing a fatty acid desaturase gene exhibit altered fatty acid profiles and improved cold tolerance. Transgenic Res 17:769-782.

Du Z, WJ Bramlage 1992 Modified thiobarbituric acid assay for measuring lipid oxidation in sugar-rich plant tissue extracts. J Agric Food Chem 40:1566-1570.

Eltayeb AE, N Kawano, GH Badawi, H Kaminaka, T Sanekata, T Shibahara, S Inanaga, K Tanaka 2007 Overexpression of monodehydroascorbate reductase in transgenic tobacco confers enhanced tolerance to ozone, salt and polyethylene glycol stresses. Planta 225: $1255-1264$.

Faize M, L Burgos, L Faize, A Piqueras, E Nicolas, G Barba-Espin, MJ Clemente-Moreno, R Alcobendas, T Artlip, JA Hernandez 2011 Involvement of cytosolic ascorbate peroxidase and $\mathrm{Cu} / \mathrm{Zn}$-superoxide dismutase for improved tolerance against drought stress. J Exp Bot 62:2599-2613.

Foyer CH, N Souriau, S Perret, M Lelandais, K-J Kunert, C Pruvost, L Jouanin 1995 Overexpression of glutathione reductase but not glutathione synthetase leads to increases in antioxidant capacity and resistance to photoinhibition in poplar trees. Plant Physiol 109: 1047-1057.

Grant OM, MJ Davies, AW Johnson, DJ Simpson 2012 Physiological and growth responses to water deficits in cultivated strawberry (Fragaria $\times$ ananassa) and in one of its progenitors, Fragaria chiloensis. Environ Exp Bot 83:23-32.

Havaux M 1992 Stress tolerance of photosystem II in vivo. Plant Physiol 100:424-432.

Herschbach C, L Rizzini, S Mult, T Hartmann, F Busch, AD Peuke, S Kopriva, I Ensminger 2010 Over-expression of bacterial $\gamma$-glutamylcysteine synthetase (GSH1) in plastids affects photosynthesis, growth and sulphur metabolism in poplar (Populus tremula $\times$ Populus alba) dependent on the resulting $\gamma$-glutamylcysteine and glutathione levels. Plant Cell Environ 7:1138-1151.

Jones HG 1992 Plants and microclimate: a quantitative approach to 
environmental plant physiology. Cambridge University Press, Cambridge.

Karpinski S, H Reynolds, B Karpinska, G Wingsle, G Creissen, P Mullineaux 1999 Systemic signalling and acclimation in response to excess excitation energy in Arabidopsis. Science 23:654-657.

Kramer DM, G Johnson, O Kiirats, GE Edwards 2004 New fluorescence parameters for the determination of quantum yield of QA redox state and excitation energy fluxes. Photosynth Res 79:209218.

Kumar S, A Dhingra, H Daniell 2004 Plastid-expressed betaine aldehyde dehydrogenase gene in carrot cultured cells, roots, and leaves confers enhanced salt tolerance. Plant Physiol 136:2843-2854.

Kwon SY, SM Choi, YO Ahn, HS Lee, HB Lee, YM Park, SS Kwak 2003 Enhanced stress-tolerance of transgenic tobacco plants expressing a human dehydroascorbate reductase gene. J Plant Physiol 160:347-353.

Larcher W 1995 Physiological plant ecology. Springer, London.

Le Martret B, M Poage, K Shiel, G Nugent, PJ Dix 2011 Tobacco chloroplast transformants expressing genes encoding dehydroascorbate reductase, glutathione reductase, and glutathione-S-transferase, exhibit altered anti-oxidant metabolism and improved abiotic stress tolerance. Plant Biotechnol J 9:661-673.

Leshem Y 1992 Plant membranes: a biophysical approach to structure, development and senescence. Kluwer Academic, Dordrecht.

Lichtenthaler HK, JA Miehé 1997 Fluorescence imaging as a diagnostic tool for plant stress. Trends Plant Sci 2:316-320.

Long SP, S Humphries, PG Falkowski 1994 Photoinhibition of photosynthesis in nature. Annu Rev Plant Physiol Plant Mol Biol 45: 633-662.

Mancini A, A Buschini, FM Restivo, C Rossi, P Poli 2006 Oxidative stress as DNA damage in different transgenic tobacco plants. Plant Sci 170:845-852.

Maxwell K, GN Johnson 2000 Chlorophyll fluorescence: a practical guide. J Exp Bot 51:659-668.

Mittler R, S Vanderauwera, M Gollery, F van Breusegem 2004
Reactive oxygen gene network of plants. Trends Plant Sci 9:490498.

Mohamed E-A, T Iwaki, I Munir, M Tamoi, S Shigeoka, A Wadano 2003 Overexpression of bacterial catalase in tomato leaf chloroplasts enhances photo-oxidative stress tolerance. Plant Cell Environ 26:2037-2046.

Murashige T, F Skoog 1962 A revised medium for rapid growth and bioassays with tobacco cultures. Physiol Plant 15:473-498.

Noctor G, A Arisi, L Jouanin, K Kunert, H Rennenberg, CH Foyer 1998 Glutathione: biosynthesis, metabolism and relationship to stress tolerance explored in transformed plants. J Exp Bot 49: 623-647.

Payton P, RD Allen, N Trolinder, AS Holaday 1997 Over-expression of chloroplast-targeted Mn superoxide dismutase in cotton (Gossypium hirsutum L., cv. Coker 312 ) does not alter the reduction of photosynthesis after short exposures to low temperature and high light intensity. Photosynth Res 52:233-242.

Payton P, R Webb, D Kornyeyev, R Allen, AS Haladay 2001 Protecting cotton photosynthesis during moderate chilling at high light intensity by increased chloroplastic antioxidant enzyme activity. J Exp Bot 52:2345-2354.

Poage M, B Le Martret, MAK Jansen, GD Nugent, PJ Dix 2011 Modification of reactive oxygen species scavenging capacity of chloroplasts through plastid transformation. Plant Mol Biol 76:371-384.

Prasad TK, MD Anderson, BA Martin, CR Stewart 1994 Evidence for chilling-induced oxidative stress in maize seedlings and a regulatory role for hydrogen peroxide. Plant Cell 6:65-74.

Raven JA 2011 The cost of photoinhibition. Physiol Plant 142:87104.

Yong Z, T Hao-Ru, L Ya 2008 Variation in antioxidant enzyme activities of two strawberry cultivars with short-term low temperature stress. World J Agric Sci 4:458-462.

Yoshimura K, K Miyao, A Gaber, T Takeda, H Kanaboshi, H Miyasaka, S Shigeoka 2004 Enhancement of stress tolerance in transgenic tobacco plants overexpressing Chlamydomonas glutathione peroxidase in chloroplasts or cytosol. Plant J 37:21-33. 
Copyright of International Journal of Plant Sciences is the property of University of Chicago Press and its content may not be copied or emailed to multiple sites or posted to a listserv without the copyright holder's express written permission. However, users may print, download, or email articles for individual use. 